\title{
PENGARUH MEDIA PEMBELAJARAN VISUAL TERHADAP HASIL BELAJAR EKONOMI SISWA
}

\author{
Oleh: Della Sari ${ }^{1}$, Neta Dian Lestari ${ }^{2}$ \\ (UNIVERSITAS PGRI PALEMBANG) \\ ${ }^{1)}$ dellasari@gmail.com, ${ }^{2)}$ neta_obyta@yahoo.com
}

\begin{abstract}
Abstrak-Media Visual merupakan media yang memiliki unsur utama berupa garis, bentuk, warna, dan tekstur dalam penyampaiannya. Tujuan dari penelitian ini untuk mengatahui Pengaruh Media Pembelajaran Visual Terhadap Hasil Belajar siswa kelas XI IPS Pada Mata Pelajaran Ekonomi di SMA Negeri 1 Martapura Tahun Pelajaran 2018/2019. Metode Penelitian yang digunakan adalah metode ekperimen yang perhitungannya menggunakan metode kuantitatif. Teknik pengumpulan data yang digunakan teknik dokumentasi, observasi dan tes. Hasil penelitian menunjukkan bahwa thitung 4,921 > ttabel 1,697, maka tolak Ho diterima Ha berarti dapat disimpulkan ada pengaruh yang signifikan antara media pembelajaran visual terhadap hasil belajar siswa di SMA Negeri 1 MartapuraTahun Pelajaran 2018/2019, maka besar tingkat interprestasi pengaruh adalah 29,455\% pada kriteria rendah sedangkan sisanya 70,545\% di penagrahui faktor lain. Sedangkan besar koefisien korelasi atau keeratan hubungan $54 \%$ pada kriteria sedang.
\end{abstract}

Kata Kunci: Media Visual, Hasil Belajar.

Abstract-Visual Media is a media that has the main elements in the form of lines, shapes, colors, and textures in its delivery. The purpose of this study was to find out the Effect of Visual Learning Media on Learning Outcomes of Social Sciences XI students in Economic Subjects in SMA Negeri 1 Martapura Academic Year 2018/2019. The research method used is the experimental method whose calculation uses quantitative methods. Data collection techniques used are documentation, observation and test techniques. The results showed that $t_{\text {hitung }}$ $4,921>t_{\text {tabel }} 1,697$, then Ho refused to accept Ha means it can be concluded that there was a significant effect between visual learning media on student learning outcomes in Martapura 1 Senior High School Year 2018/2019, then the level of interpretation influence was $29.455 \%$ on the criteria low while the remaining $70.545 \%$ is determined by other factors. While the correlation coefficient or closeness is $54 \%$ in the medium criteria.

Keywords: Visual Media, Learning Outcomes.

PENDAHULUAN

Guru diharapkan mampu mengembangkan inovasi dan kreativitas dalam rangka mewujudkan tujuan pembelajaran yang sesuai dengan tujuan pendidikan nasional. Namun, tidak dapat dipungkiri bahwa masih 
banyak hambatan bagi guru untuk menerapkan sistem pendidikan berbasis peserta didik. Hambatan yang umumnya ditemui oleh para guru adalah melakukan variasi ketika kegiatan pembelajaran berlangsung. Dalam penggunaan media pendidik terkadang kurang menguasai dan tidak menggunakannya secara efektif dan efisien.

Guru cenderung melaksanakan kegiatan pembelajaran dengan media pembelajaran konvensional yang menjadikan peserta didik sebagai objek, yaitu peserta didik lebih banyak mencatat, dan mendengarkan ceramah materi dari guru, tanpa diimbangi variasi media pembelajaran yang menarik bagi peserta didik. Adanya hambatan semacam ini yang mengakibatkan peserta didik kurang aktif berpartisipasi dalam proses belajar mengajar, peserta didik tidak dapat fokus pada materi yang diajarkan dan rasa bosan untuk belajar semakin meningkat, sehingga motivasi dan hasil belajar peserta didik pun kurang baik.

Menurut Hamalik dalam Arsyad (2011:15) bahwasannya pemakaian media pembelajaran dalam proses belajar mengajar dapat membangkitkan keinginan dan minat yang baru, membangkitkan motivasi dan rangsangan kegiatan mengajar, bahkan membawa pengaruhpengaruh psikologis terhadap siswa. Sedangkan menurut Sedangkan menurut Criticos dalam Daryanto
(2011:4) media merupakan salah satu komponen komunikasi, yaitu sebagai pembawa pesan dari komunikator menuju komunikan.

Berdasarkan hal tersebut media pembelajaran merupakan suatu alat atau perantara yang berguna untuk memindahkan proses belajar mengajar, dalam rangka mengefektifkan komunikasi antara guru dan siswa. Hal ini sangat membantu guru dalammengajar dan memudahkan siswa menerima dan memahami pembelajaran. Proses ini membutuhkan guru yang mampu menyesuaikan antara media pembelajaran dan metode pembelajaran.

Menurut Sanjaya (2008:211) Media visual adalah media yang hanya dapat dilihat saja, tidak mengandung unsur suara. Yang termasuk ke dalam media visual adalah film slide, foto, transparasi, lukisan, gambar dan berbentuk bahan yang dicetak seperti media grafis. Media visual merupakan sebuah media yang memiliki beberapa unsur berupa garis, bentuk, warna, dan tekstur dalam penyajianya. Bentuk visual berupa : 1) Gambar representasi seperti gambar, likusan atau foto yang menunjukkan bagaiman tampaknya sesuatu benda. 2) Diagaram yang melukiskan hubungan-hubungan konsep, organisasi dan struktur isi materia. 3) Peta yang menunjukan hubunganhubungan ruang antara unsur-unsur dalam isi materi. 4) Grafik seperti 
tabel, grafik dan chart (bagan) yang menyajikan gambaran atau kecenderungan data atau antar hubungan seperangkat gambar atau angka-angka (Arsyad. 2013:89).

Menurut Arief S. Sadiman, dkk (2011:84) mengemukakan pemilih media antara lain adalah a) bermaksud mendemonstrasikannya seperti halnya pada kuliah tentang media, b) merasa sudah akrab dengan media tersebut, misalnya seorang dosen yang sudah terbiasa menggunakan proyektor transparansi, c) ingin memberi gambaran atau penjelasan yang lebih konkret, dan d) merasa bahwa media dapat berbuat lebih dari yang bisa dilakukan, misalnya untuk menarik minat atau gairah belajar siswa.

Berdasarkan hal tersebut Media visual alat bantu dapat mewakili sesuatu yang tidak dapat disampaikan guru melalui kata-kata atau kalimat, dan siswa dapat memahami pembelajaran ekonomi. Dengan memanfaatkan media pembelajaran visual, guru dapat menggairahkan minat belajar siswa. Pemakaian media pembelajaran dalam proses belajar mengajar dapat membangkitkan motivasi dan minat yang baru bagi siswa untuk belajar dengan baik. Selain dapat motivasi belajar peserta didik, pemakaian atau pemanfataan media juga dapat meningkatkan pemahaman peserta didik terhadap pelajaran.

Kenyataan tersebut diatas menunjukkan adanya suatu masalah dalam pembelajaran Ekonomi kelas XI IPS 1 SMA Negeri 1 Martapura, siswa kurang memiliki motivasi untuk belajar dan memahami materi Ekonomi dengan baik sehingga hasil belajar Ekonomi cenderung rendah. Guna menyelesaikan permasalahan media pembelajaran yang bersifat konvensional, pemahaman siswa yang masih kurang, motivasi dan hasil belajar siswa yang masih rendah, maka diperlukan suatu media pembelajaran yang lebih efektif dan lebih menekankan pada keaktifan belajar siswa pada kegiatan pembelajaran.Salah satu alternatif yang dapat diterapkan adalah melalui penerapan Media visual.

Berdasarkan hasil observasi awal yang dilakukan di SMA Negeri 1 Martapura, peran guru disini masih sangat besar atau guru sebagai sumber pembelajaran dimana guru meyampaikan pembelajaran secara konvensinal yaitu bahan pelajaran sebagian besar disampaikan melalui ceramah. Hasil belajar siswa baik tetapi akan lebih baik lagi jika pembelajarannya terus ditingkatkan dan dikembangkan lagi. Dari pemasalahan yang dialami siswa seperti yang diuraikan diatas maka peneliti mengadakan peneliti dengan judul "Pengaruh Media Pembelajaran Visual Terhadap Hasil Belajar Siswa Kelas XI IPS Pada Mata Pelajaran Ekonomi Di SMA Negeri 1 Martapura Tahun Pelajaran 2018/2019". 


\section{METODE PENELITIAN}

"Metode penelitian adalah cara yang digunakan oleh peneliti dalam mengumpulkan data penelitiannya"(Arikunto,2014:203). Pelaksanaan dalam penelitian ini metode yang digunakan adalah metode eksperimen yang perhitungannya menggunakan metode kuantitatif. Pelaksanaan dalam metode penelitian ini peneliti bertujuan melihat adakah pengaruh media pembelajaran visual terhadap hasil belajar siswa pada mata pelajaran ekonomi kelas X1 di SMA Negeri 1 Martapura Tahun Pelajaran 2018/2019.

Analisis data observasi dimaksudkan untuk mengukur tingkat persentase aktivitas siswa dalam proses pembelajaran. Dalam menganalisa hasil observasi atau pengamatan dilihat melalui dilaksanakan atau tidaknya aktivitas belajar tersebut oleh siswa selama proses pembelajaran berlangsung. Hasil observasi tersebut selanjutnya dihitung dengan menggunakan rumus:

$$
N A=\frac{S}{S M} \times 100
$$

(Purwanto, 2009:102)

Keterangan:

NA :Nilai Akhir

S :Skor Observasi

SM :Skor Maksimal

\section{HASIL DAN PEMBAHASAN}

Penelitian ini dilaksanakan di SMA Negeri 1 Martapura yang terletak di. Jln SMA Kotabaru Barat Martapura Ogan Komering Ulu Timur. Populasi penelitian ini adalah seluruh kelas XI IPS yang berjumlah 113 siswa. Dalam penetapan kelas XI di SMA Negeri 1 Martapura tidak berdasarkan peringkat ataupun dari kelas unggulan sehingga sama. Sampel penelitian ini diambil menggunakan teknik simplerandom sampling atau sistem acak, yaitu dari 4 kelas XI dilakukan pengundian untuk menentukan dua kelas yang akan dijadikan kelas eksperimen dan kelas kontrol. Hasil pengundian diperoleh kelas $\mathrm{X}$ IPS 1 yang berjumlah 30 siswa sebagai kelas eksperimen dan kelas X IPS 2 sebagai kelas kontrol yang berjumlah 30 siswa.

Dalam penelitian ini peneliti menggunakan 3 teknik dalam pengumpulan data yaitu, teknik dokumentasi, observasi dan teknik tes. Teknik dokumentasi yang diambil berupa informasi mengenai data tentang jumlah siswa, namanama siswa, populasi gambaran umum sekolah, jumlah guru dan pegawai di SMA Negeri 1 Martapura. Teknik observasi digunakan untuk mendapatkan datadata dan pengamatan penilaian aktivitas belajar siswa saat berlangsungnya proses pembelajaran. Sedangkan teknik tes digunakan untuk mendapatkan data mengenai 
hasil belajar siswa setelah mengikuti kegiatan pembelajaran menggunakan media pembelajaran visual.

Penelitian ini dilakukan sebanyak tiga kali pertemuan, dengan dua kali pertemuan untuk kegiatan pembelajaran dan ketiga kalinya diadakan tes untuk melihat hasil belajar siswa setelah mengikuti proses pembelajaran.

Dari lampiran yang menyajikan rata-rata persentase keaktifan siswa pada kelas XI IPS 1 yang belajar menggunakan media pembelajaran visual dan kelas XI IPS 2 yang belajar tanpa menggunakan media visual, maka dapat diketahui bahwa $13,33 \%$ siswa dikelas XI IPS 1 tergolong sangat aktif yakni 4 siswa, dan yang tergolong dalam ruang lingkup aktif diketahui sebanyak 26 siswa atau sama dengan $86,87 \%$ dari jumlah siswa kelas XI IPS 1 yang diobservasi. Sedangkan pada kelas XI IPS 2 yang belajar tanpa menggunakan media visual diketahui presentasi siswa yang sangat aktif hanya 2 orang atau sebesar $6,67 \%$ dari jumlah siswa yang mengikuti pembelajaran, dan yang termasuk dalam kategori aktif cukup banyak yakni berjumlah 28 orang atau dengan presentase $93,33 \%$ dari jumlah siswa yang mengikuti pembelajaran di kelas XI IPS 2. Jadi dapat disimpulkan bahwa tingkat keaktifan siswa antara penggunaan media pembelajaran visual dengan tanpa menggunakan media visual terdapat perbedaan, yakni presentase siswa yang sangat aktif lebih banyak pada kelas XI IPS 1 yang menggunakan media pembelajaran visual daripada kelas XI IPS 2 yang tanpa menggunakan media visual.

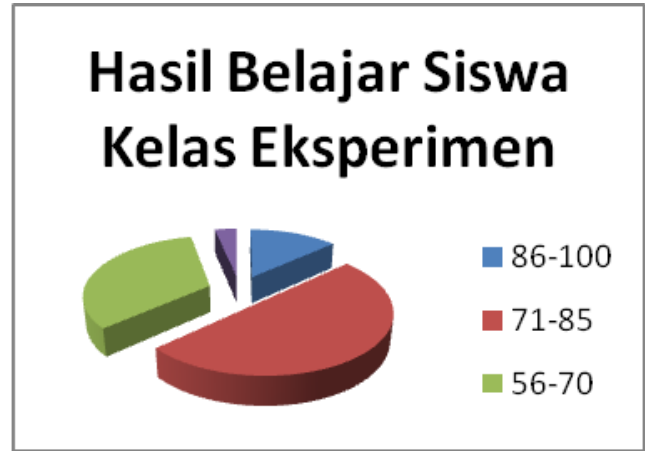

Gambar 1. Presentase Hasil Belajar Siswa Kelas Eksperimen.

Berdasarkan hasil tes diketahui bahwa jumlah siswa pada kelas XI IPS 1 adalah 30 siswa, jumlah siswa yang memperoleh nilai antara 86 - 100 berjumlah 4 orang dengan presentase $13,33 \%$, siswa yang mendapatkan nilai $71-85$ berjumlah 15 orang dengan presentase $50 \%$, siswa yang mendapatkan nilai 56 - 70 berjumlah 10 orang dengan presentase $33,33 \%$, Serta siswa yang memperoleh nilai antara $41-55$ berjumlah 1 orang dengan presentase $0,11 \%$. 


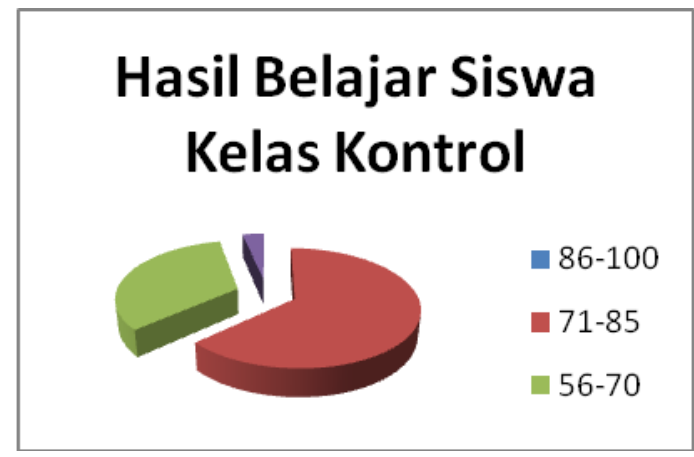

\section{Gambar 2. Presentase Hasil Belajar Siswa Kelas Kontrol}

Berdasarkan hasil tes diketahui bahwa jumlah siswa pada kelasXI IPS 2 yang belajar tanpa menggunakan media visual frekuensi siswa yang mendapatkan nilai 86 100 berjumlah orang dengan presentase $0 \%$, siswa yang mendapatkan nilai $71-85$ berjumlah 19 orang dengan presentase $63,33 \%$, siswa yang mendapatkan nilai 56 70 berjumlah 10 orang dengan presentase $33,33 \%$, serta siswa yang memperoleh nilai antara 41 - 55 berjumlah 1 orang dengan presentase $3,33 \%$.

Berdasarkan data yang diperoleh dari observasi yang dilakukan pada kelas XI IPS 1 dan XI IPS 2 maka keaktifan siswa pada kelas XI IPS 1 yang belajar menggunakan media pembelajaran visual dan kelas XI IPS 2 yang belajar tanpa menggunakan media visual, maka dapat diketahui bahwa $13,33 \%$ siswa dikelas XI IPS 1 tergolong sangat aktif yakni 4 siswa, dan yang tergolong dalam ruang lingkup aktif diketahui sebanyak 26 siswa atau sama dengan $86,87 \%$ dari jumlah siswa kelas XI IPS 1 yang diobservasi. Sedangkan pada kelas XI IPS 2 yang belajar tanpa menggunakan media visual diketahui presentasi siswa yang sangat aktif hanya 2 orang atau sebesar $6,67 \%$ dari jumlah siswa yang mengikuti pembelajaran, dan yang termasuk dalam kategori aktif cukup banyak yakni berjumlah 28 orang atau dengan presentase $93,33 \%$ dari jumlah siswa yang mengikuti pembelajaran di kelas XI IPS 2.

\section{Uji Prasyarat}

\section{a. Uji Normalitas Data}

Jarak $/$ range $/$ rentang $=$ nilai terbesar - nilai terendah $=100-50=$ 50

1) Banyak kelas telah ditentukan 6 yang sesuai dengan normal

2) Panjang kelas interval

$$
\text { (i) }=\frac{\text { rentang }}{\text { banyak kelas }}=\frac{50}{6} 8,3=8
$$

3) Menghitung Chi Kuadrat $\left(X^{2}\right.$ 
Tabel 1. Pembantu Menghitung Normalitas

\begin{tabular}{|c|c|c|c|c|c|}
\hline No & Interval & $\boldsymbol{f}_{\mathbf{0}}$ & $\boldsymbol{f}_{\mathbf{h}}$ & $\boldsymbol{f}_{\mathbf{0}}-\boldsymbol{f}_{\mathbf{h}}$ & $\frac{\left(f \circ-f \mathrm{f}^{2}\right.}{f h}$ \\
\hline 1 & $50-57$ & 3 & $2,35 \% \times 60=1,41$ & 1,59 & 1,79 \\
\hline 2 & $58-65$ & 8 & $13,50 \% \times 60=8,1$ & 0,1 & 0,001 \\
\hline 3 & $66-73$ & 12 & $34 \% \times 60=20,4$ & $-8,4$ & 3,46 \\
\hline 4 & $74-81$ & 25 & $34 \% \times 60=20,4$ & 4,6 & 1,037 \\
\hline 5 & $82-89$ & 10 & $13,50 \% \times 60=8,1$ & 1,9 & 0,45 \\
\hline 6 & $90-100$ & 2 & $2,35 \% \times 60=1,41$ & 0,59 & 0,25 \\
\hline$\sum$ & & 60 & 60 & & 6,99 \\
\hline
\end{tabular}

Sumber: Hasil Olah Penelitian

Kesimpulan :

$X^{2} \mathrm{t}_{\text {hitung }}=\frac{(f \circ-f \mathrm{~h})^{2}}{f h}=6,99$

$X^{2} \mathrm{t}_{\text {tabel }}=\alpha 0,05 / 2 \mathrm{dk} 6-1=11,070$

$X^{2} \mathrm{t}_{\text {hitung }}=6.99<X^{2} \mathrm{t}_{\text {tabel }} \alpha 0,05 / 2 \mathrm{dk} 6-1=11,070$ maka disimpulkan data hasil belajar berdistribusi normal karena $X^{2}{ }_{\text {hitung }}$ lebih kecil dari pada $\mathrm{X}_{\text {tabel. }}^{2}$

\section{b. Homogenitas Varians Data}

1. Homogenitas hasil belajar kelas eksperimen.

Berdasarkan perhitungan lampiran diperoleh homogenitas varians data siswa kelas eksperimen adalah :

$\mathrm{n}_{1}=30 \quad \mathrm{X}_{1}=2420$

$\left(\mathrm{X}_{1}\right)^{2}=198800$

2. Homogenitas hasil belajar kelas kontrol

Berdasarkan perhitungan lampiran diperoleh homogenitas varians data siswa kelas kontrol adalah :

$\mathrm{n}_{1}=30$ $X_{1}=2057$

$\left(X_{1}\right)^{2}=143120$
3. Mencari homogenitas varians siswa kelas eksperimen dan kelas control.

Standar devisi hasil belajar kelas eksperimen

$$
\begin{aligned}
\int_{1}^{2} & =\frac{198800-\frac{2420^{2}}{30}}{30-1} \\
& =\frac{198800-195213}{29}=123,689
\end{aligned}
$$

Standar devisi hasil belajar kelas kontrol

$$
\begin{aligned}
\int_{2}^{2} & =\frac{143120-\frac{2057^{2}}{30}}{30-1} \\
& =\frac{143120-141041}{29}=71,689
\end{aligned}
$$

Harga $F_{\text {hitung }}$

$\mathrm{F}=\frac{\text { varians terbesar }}{\text { varians terkecil }}$ 


$$
\begin{aligned}
& \mathrm{F}_{\text {hitung }}=\frac{123,689}{71,689}=1,725 \\
& \mathrm{~F}_{\text {tabel }} \alpha 0,05 / 2 \mathrm{dk} 30-1 / \mathrm{dk} 30-1= \\
& \quad 1,88
\end{aligned}
$$

Kesimpulan :

$\mathrm{F}_{\text {hitung }}=1,725<\mathrm{F}_{\text {tabel }}=1,88$, berarti $F_{\text {hitung }}$ yaitu1,725 lebih kecil dari $F_{\text {tabel }}$ yaitu 1,88 maka data varians terbukti homogen.

\section{Uji Hipotesis}

Data berdistribusi normal dan varians data homogen, maka dapat digunakan statistik parametris. Statistik yang digunakan adalah uji " $t$ " tes melalui regresi linear sederhana.

Berdasarkan lampiran diketahui sebagai berikut :

$$
\begin{array}{lll}
\mathrm{n}=60 & \sum \mathrm{Y}=4477 & \sum \mathrm{XY}=2420 \\
\sum \mathrm{X}=3 & \sum \mathrm{Y}^{2}=341553 & \sum \mathrm{X}^{2}=30 \\
\bar{Y}=74,61 & \overline{\mathrm{X}}=0,5 &
\end{array}
$$

Dari data di atas dapat dihitung :

$$
\begin{aligned}
\sum x^{2} & =\sum X^{2}-\frac{\left(\sum X\right)^{2}}{n}=30-\frac{30^{2}}{60}=15 \\
\sum y^{2} & =\sum \mathrm{Y}^{2}-\frac{\left(\sum \mathrm{Y}\right)^{2}}{n} \\
& =341553-\frac{(4477)^{2}}{60} \\
& =341553-334058=7495 \\
\sum x y & =\sum \mathrm{XY}-\frac{\left(\sum \mathrm{X}\right)\left(\sum \mathrm{Y}\right)^{2}}{\mathrm{n}} \\
& =2420-\frac{(30)(4477)}{60} \\
& =2420-223=182
\end{aligned}
$$

1) Menghitung harga $b$ dan $a$

$$
\mathrm{b}=\frac{\sum x y}{\sum x^{2}}=\frac{182}{15}=12,13
$$

$$
\begin{aligned}
\mathrm{a} & =\bar{Y}-\mathrm{b} \overline{\mathrm{X}}=74,61-12,13(0,5) \\
& =74,61-6,065 \\
& =68,54
\end{aligned}
$$

2) Standar eror regresi (Se)

$$
\begin{aligned}
\mathrm{S}_{\mathrm{e}}{ }^{2} & =\frac{\sum \gamma^{2}-b \sum x y}{n-2} \\
\mathrm{~S}_{\mathrm{e}}{ }^{2} & =\frac{7495-12,13(182)}{60-2}=\frac{7495-2207}{58} \\
& =91,17
\end{aligned}
$$

3) Standar eror koefisien regresi $(\mathrm{Sb})$

$$
\begin{aligned}
& S_{b}=\frac{S_{a}^{2}}{\sum \chi^{2}} \\
& S_{b}=\sqrt{\frac{91,17}{15}}=\sqrt{6,078}=2,465
\end{aligned}
$$

4) Harga $t_{\text {hitung }}$

$$
\begin{aligned}
& \mathrm{t}_{\text {hitung }}=\frac{b}{s b} \\
& \mathrm{t}_{\text {hitung }}=\frac{12,13}{2,465}=4,921
\end{aligned}
$$

5) Koefisien detirminasi $\left(r^{2}\right)$ atau besarnya pengaruh

$$
\begin{aligned}
r^{2} & =\frac{b \sum \chi \gamma}{\sum \gamma^{2}} \\
r^{2} & =\frac{12,13(182)}{7495}=\frac{2207,6}{7495} \\
& =0,29455=29,455 \%
\end{aligned}
$$

Koefisien korelasi (keeratan hubungan)

$$
\begin{aligned}
r & =\sqrt{r^{2}}=\sqrt{0,29455} \\
& =0,54 \text { atau } 54 \%
\end{aligned}
$$

6) $t_{\text {hitung }} 4,921>t_{\text {tabel }} 1,697$, maka tolak Ho diterima Ha berarti dapat disimpulkan ada pengaruh yang signifikan antara media pembelajaran visual terhadap hasil belajar siswa di SMA Negeri 1 Martapura Tahun Pelajaran 2018/2019, maka besar tingkat 
interprestasi pengaruh adalah $29,455 \%$ dengan kriteria rendah sedangkan sisanya $70,545 \%$ di penagrahui faktor lain. Sedangkan besar koefisien korelas atau keeratan hubungan $54 \%$ dengan criteria sedang.

Berdasarakan dari hasil analisis tes akhir baik dikelas eksperimen maupun kelas kontrol sesuai dengan hasil belajar siswa diperoleh rata-rata pada kelas eksperimen yang diberikan perlakuan yaitu media pembelajaran visual sebesar 81 dalam kategori "baik ", Ini disebabkan karena dalam media ini memberikan kesempatan untuk siswa aktif dalam berfikir, ketrampilan bertanya dan mengemukakan pendapat sedangkan untuk kelas kontrol tanpa menggunakan media sebesar 68,5 dalam kategori "cukup", ini disebabkan karena dalam pembelajaran konvensional ini hanya menggunakan metode ceramah, tanya jawab. Dilihat dari persentase yang didapat maka terlihat bahwa ketercapaian untuk kelas eksperimen lebih besar dari kelas kontrol yang hanya menggunakan tanpa media pembelajaran . Selisih rata-rata antara kelas eksperimen dengan kelas kontrol sebesar 12,5 dipengaruhi dengan faktor lain.

\section{KESIMPULAN DAN SARAN}

Berdasarkan data observasi maka diketahui nilai rata-rata keaktifan siswa pada kelas XI IPS 1 yang belajar menggunakan media pembelajaran visual termasuk kategori sangat aktif sebanyak 4 orang dengan persentase 13,33\%. Sedangkan pada kelas XI IPS 2 yang belajar tanpa menggunakan media visual termasuk kategori sangat aktif sebanyak 2 orang dengan persentase $6,67 \%$.

Berdasarkan hasil penelitian yang telah dilakukan oleh peneliti maka diketahui terdapat perbedaan hasil belajar siswa pada mata pelajaran ekonomi dengan menggunakan media pembelajaran visual dengan tanpa menggunakan media pembelajaran visual tahun pelajaran 2018/2019. Hal ini terlihat dari hasil perhitunganuji $t$ yaitu $t_{\text {hitung }}$ $=4,921>\mathrm{t}_{\text {tabel }}=1,697$ maka Ho ditolak dan terima $\mathrm{Ha}$

Berdasarkan analisis dari hasil penelitian yang telah dilakukan, maka dapat diketahui bahwa pada mata pelajaran ekonomi dengan materi pendapatan nasional penggunaan media pembelajaran visuallebih baik daripada tanpa menggunakan media pembelajaran visual.

Peneliti memberikan saran kepada guru untuk dijadikan salah satu alternatif meningkatkan hasil belajar dan bagi peneliti selanjutnya agar bisa dikembangkan dan dijadikan sebagai acuan untuk penelitian selanjutnya agar lebih baik lagi. 


\section{DAFTAR PUSTAKA}

Arif S. Sadiman, dkk. 2011. Media

Pendidikan, Pengertian,

Pengembangan, dan

Pemanfaatannya. Jakarta: PT.

Raja Grafindo Persada.

Arikunto, Suharsimi. 2010. Prosedur

Penelitian

(Edisi

Revisi).Jakarta: Rineka Cipta.

Arsyad, Azhar. 2014. Media

Pembelajaran. Jakarta : PT

Raja Grafindo Persada.

Arsyad.2013. Media Pembelajaran.

Jakarta: Rajawali Pers.

Daryanto. 2014. Pendekatan

Pembelajaran Saintifik

Kurikulum 2013. Yogyakarta:

Penerbit Gava Media.

Sanjaya, Wina. 2008. Perencanaan

Dan Desain Sistem

Pembelajaran. Bandung:

kencana prenada media group.

Purwanto. 2009. Evaluasi Hasil

Belajar. Surakarta: Pustaka

Belajar 